\title{
Differences in Happiness after Early Crawling Experience
}

\author{
Anne H. Zachry ${ }^{1}$, Rebecca L. Goldman ${ }^{1}$, Nikki F. Gordon ${ }^{1}$, \\ Stephanie B. Lancaster ${ }^{1}$, Kayla B. Simpson ${ }^{1} \&$ Sarah K. Springer ${ }^{1}$ \\ ${ }^{1}$ Department of Occupational Therapy, University of Tennessee Health Science Center, Memphis, TN USA \\ Correspondence: Anne H. Zachry, Department of Occupational Therapy, University of Tennessee Health \\ Science Center, Memphis, TN, USA. Tel: 1-901-448-2228. E-mail: azachry@uthsc.edu
}

Received: April 21, 2015

Accepted: May 21, $2015 \quad$ Online Published: September 28, 2015

doi:10.5539/jedp.v5n2p8

URL: http://dx.doi.org/10.5539/jedp.v5n2p8

\begin{abstract}
The purpose of this study was to examine differences in happiness between precrawlers and crawlers. Previous literature has addressed the emotional development of typical developing infants; however, there is limited research on the specific emotion of happiness in infancy as it relates to crawling. Independent locomotion affords infants opportunities to explore distant contexts, set and meet goals, and interact socially interact with individuals that are not in close proximity, all which influence social and emotional development. The examination detailed in this article builds on previous research through the observation of typically developing precrawlers and crawlers in the context of day care settings, allowing for observations of social interactions. Using a mixed-methods design, when matched on age and gender, a paired samples t-test revealed no differences in mean happiness scores between precrawlers and crawlers. A cross-case analysis revealed an increase in happiness with the onset of crawling followed by a drop in happiness to just below baseline after 4 weeks of crawling experience.
\end{abstract}

Keywords: happiness, crawling, emotional development

\section{Introduction}

The onset of independent mobility has been referred to as the event that triggers the psychological birth of an infant (Mahler, Pine, \& Bergman, 1975). The milestone of crawling transforms an infant's social and physical world by expanding interactions to include a variety of objects, people, and settings (Campos et al., 2000; Whitney \& Green, 2011). Research suggests that independent mobility impacts social referencing, perception, social interactions, memory, parental expectations of infant behavior, and brain activity (Bell \& Fox, 1996; Campos, Kermoian, \& Zumbahlen, 1992; Clearfield, 2011; Hendrix \& Thompson, 2011; Herbert, Gross, \& Hayne, 2007).

As typical infants progress through development, they also experience emotional changes following experience with crawling (Lewis \& Michalson, 1983). For example, mothers have reported increased affection and anger in infants who have just mastered independent mobility (Campos, Bertenthal, \& Kermoian, 1992). Studies related to fear and the visual cliff reveal that a fear of heights only emerges until after crawling experience (Campos, Hiatt, Ramsay, Henderson, \& Svejda, 1978).

Campos et al. (1992) reported the socio-emotional behaviors change with the onset of mobility in infancy, with the child often mirroring the emotions of others once the baby has begun crawling. For example, a child may become happier as the result of observing the parents' happiness (Campos et al., 1992). In one study, Whitney and Green (2011) proposed that once infants gained independent locomotion, an increase in both positive and negative expressions during free play occurred (Whitney \& Green, 2011). During monthly observations, the authors analyzed and coded infant facial expressions and vocalizations as negative or positive. Data analysis revealed that negative affect decreased during free play across four time points after the onset of mobility (Whitney \& Green, 2011); however, the parents in the study reported that their infants displayed an increase in both positive and negative emotions after crawling experience. The investigators suggested that this difference in findings might be because the mothers in the study had opportunities to observe their infants in various contexts, while the researcher observers only observed during designated observation periods. 
Considering that independent mobility significantly influences many aspects of development, it is important to understand how mobility in the form of crawling is related to specific emotional processes. The aim of the present study was to determine differences between happiness in a group of precrawling and crawling infants. Extensive research exists related to emotional development throughout the progression of infancy, but, as indicated above, there are limited studies that compare the specific emotion of happiness in precrawlers and crawlers. The present examination extends existing research by examining the specific emotion of happiness in typically developing precrawlers and crawlers in the context of day care settings, allowing for observation of social interactions. The authors proposed that crawling infants have more opportunities for goals to be fulfilled and for social interaction, leading to an increase in happiness as compared to precrawlers (Zachry \& Mitchell, 2012).

\section{Method}

\subsection{Participants}

The subjects in this study were drawn from a convenience sample in a larger investigation that examined the effects of crawling on emotional development in infancy. The sample for the current study included 44 subjects (59\% female) with ages ranging from 32 to 44 months $($ mean $=36.95 ; \mathrm{SD}=4.01)($ See Table 1$)$.

Table 1. Demographic information for precrawlers and crawlers

\begin{tabular}{lccllllll}
\hline \multicolumn{3}{c}{ Gender $(\%)$} & & & \multicolumn{3}{c}{ Ethnicity (\%) } \\
\hline & Boys & Girls & $\begin{array}{l}\text { Age } \\
(\text { weeks) }\end{array}$ & Mean (SD) & Range & White & $\begin{array}{l}\text { African } \\
\text { American }\end{array}$ & Asian \\
Precrawlers $(\mathrm{n}=22)^{*}$ & 40.9 & 59.1 & 45.2 & $36(3.46)$ & $30-44$ & 86.4 & 1 & .5 \\
Crawlers $(\mathrm{n}=22)^{*}$ & 40.9 & 59.1 & 51.5 & $37.6(4.37)$ & $30-44$ & 95.5 & .5 & 0 \\
\hline
\end{tabular}

The infants were divided into two groups: crawlers and precrawlers, with the following prerequisites required: (1) one group had no experience with the skill of independent mobility; (2) the second group had a minimum of four weeks of experience with crawling, as determined by parental survey; and (3) each precrawling subject was required to have an gender and age match to that of a crawling subject. Research by Campos et al. (1992) revealed that infants demonstrated emotional changes, including a wariness of heights, four weeks after crawling onset. In keeping with this research, it was proposed that differences in happiness would be present after a minimum of four weeks of crawling experience; therefore, the time period of four weeks was used as the benchmark in the current study.

\subsection{Procedure}

Prior to initiating the study, the investigators secured IRB approval, and the primary investigator obtained consent from the parents and childcare agency administration. Only one caregiver denied consent, and so that child was not videotaped or used in this research study. All observations took place within the daycare centers. At a later date, secondary investigators used these videotapes to conduct observations.

Because research reveals that experience with hands-and-knees crawling is associated with successful object-search paradigm, while belly crawling is not (Bai \& Bertenthal, 1992; Kermoian \& Campos, 1988). For the purposes of this study, crawling was defined as independent forward movement of an infant using a hands-and-knees gait with the belly suspended off the floor (Adolf, Vereijken, \& Denny, 1998).

At the initiation of the study, two male and one female Caucasian precrawlers were selected from the precrawling sample infants for longitudinal bimonthly observations until hands-and-knees crawling was mastered. Descriptive notes from the longitudinal observations supplemented the objective data. The three infants were selected because all had entered the same childcare center at eight weeks of age, and the infants were familiar with the setting and staff. On the first day of the investigation, each infant assumed a hands-and-knees position on at least one occasion without forward mobility, which is a developmental precursor to independent crawling (Folio \& Fewell, 1983). Each child was observed on a bimonthly bases until four weeks of experience with crawling was gained. The data for these three subjects was included in the sample of crawlers in the cross-sectional component of the investigation. At onset of the study, the two males were 30 and 33 weeks of age, and the female was 32 weeks old. 
Investigators used the Scales of Socioemotional Development (SSD) instrument (Lewis \& Michalson, 1983). Primary and secondary investigators utilized the SSD checklist to document which behaviors were noted during the observations. The SSD defines happiness as "positive states that are also labeled delight, joy, or pleasure" (Lewis \& Michalson, 1983, p. 273). Ten situations evoke happiness, including infant exposure to a surprise toy and participation in a game of peek-a-boo with a caregiver (See Table 2).

Table 2. Situations on the SSD that possibly provoke happiness

\author{
Child interacts with caregiver \\ Caregiver praises child \\ Child plays peek-a-boo with caregiver \\ Caregiver teases child \\ Caregiver acts silly \\ Child plays with surprise toy \\ Child sees reflection of self in mirror \\ Child sees reflection of another person in mirror \\ Music is played in room \\ Snack time
}

The SSD scales have shown strong observer reliability and high internal consistency. Lewis and Michalson (1983) reported observer reliabilities for happiness at $85 \%$. In addition, to assess interrater reliability, the four secondary investigators independently reviewed $50 \%$ of the videotapes using the SSD. One student rater was randomly selected from the four for a Kappa calculation. An interrater reliability analysis using the Kappa statistic was performed to determine consistency among raters. The result of the analysis was satisfactory, Kappa $=0.789, \mathrm{p}<0.001$.

\title{
2.3 Analysis
}

\subsubsection{Cross-Sectional Component}

Twenty-two precrawlers and crawlers were matched based on age and gender $(n=44)$, and a paired samples t-test was run to determine whether there were differences in mean happiness scores between the two groups.

\subsubsection{Case Studies}

To examine the evolution of happiness from precrawling to crawling, a multiple study cross-case examination was employed. Constant comparison and inductive analysis took place during the data collection, allowing for documentation of the transition in happiness that occurred as crawling was mastered (Le Compte \& Priessle, 1993). Through the examination of similarities and differences in happiness across the three cases, recurrent trends were identified and documented (Miles \& Huberman, 2013).

\subsubsection{Data Coding}

Analysis of the case study data began concomitantly with the data collection. The initial phase of the analysis involved developing a coding scheme using the SSD codes as a guide. Descriptive codes were utilized, which require little to no interpretation (Miles \& Huberman, 2013).

The researcher transcribed the field notes and entered the data into ATLAS.TI, a software program utilized for the analysis of varied data (Muhr \& Friese, 2004). ATLAS.TI allows investigators to explore the themes that run throughout the data by providing tools that extract, compare, manipulate and contrast significant pieces from vast data sets in a systematic manner (Muhr \& Friese, 2004). Once the documents were entered into the program, the investigator reviewed the documents and applied descriptive codes to each specific situation, behavior, and emotional expression. During the review of the documents, the investigator created memos in ATLAS.TI, documenting patterns related to changes in happiness that occurred with crawling experience.

Each document was reviewed once more, examining the behavioral context in which the emotions took place. An emotional category for happiness was coded. Using ATLAS.TI's graphic display of the codes' hierarchical 
and relational connections (Muhr \& Friese, 2004), corresponding networks of happiness were constructed across cases. The videos were reviewed a final time to follow up on any questions that arose.

\section{Results}

\subsection{Cross Sectional Analysis}

With age and gender matched, a paired samples t-test was run to determine whether there were differences in mean happiness scores between precrawlers and crawlers. Mean happiness scores were normally distributed, as assessed by Shapiro-Wilk's test $(p>.05)$ and based on the inspection of a boxplot, there were no outliers in the data. After four weeks of crawling experience, there was no significant difference in the mean happiness scores for precrawlers $(\mathrm{M}=2.86, \mathrm{SD}=.54)$ and crawlers $(\mathrm{M}=3.11, \mathrm{SD}=.57) ; \mathrm{t}(21)=-1.87, \mathrm{p}=.075$.

\subsection{Cross-Case Analysis}

Happiness increased after the onset of crawling and then dropped slightly below the initial level after four weeks of crawling experience. The final result is consistent with the statistical data that reveals no significant changes between happiness and four weeks of crawling experience (See Figure 1).

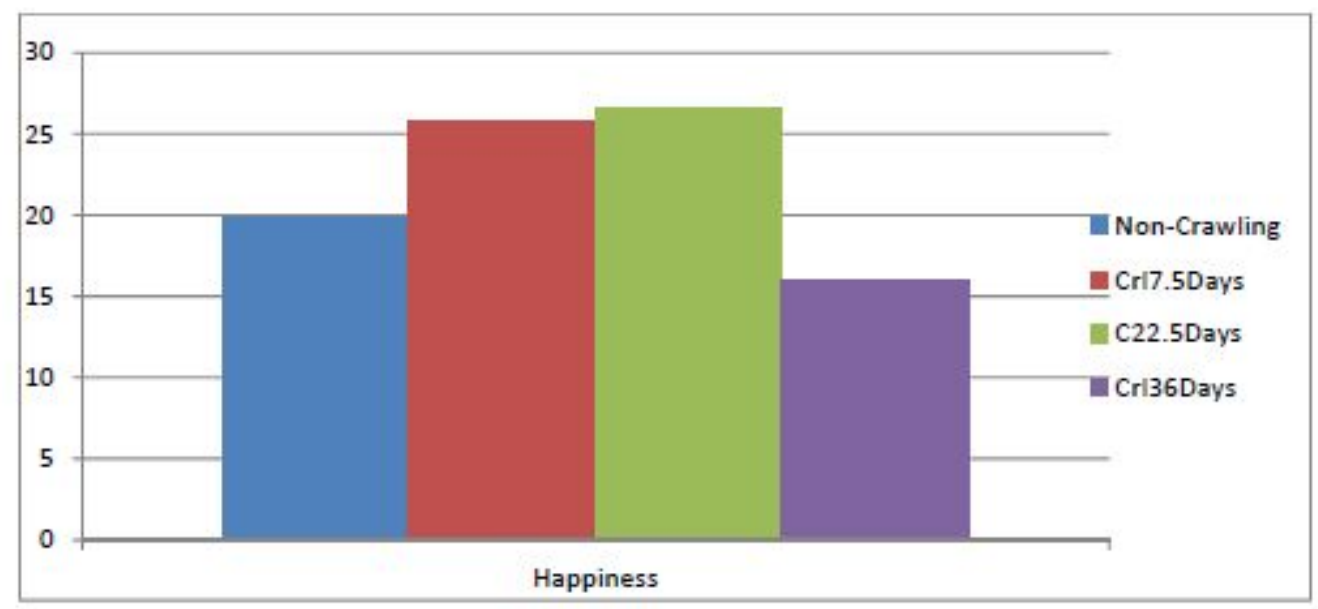

Figure 1. Trajectory of happiness for case studies

\section{Discussion}

The present investigation aimed to determine if there are differences between happiness in precrawling and crawling infants. After four weeks of experience with crawling, there were no differences in happiness between the groups. The longitudinal, cross-case analysis revealed an increase in happiness during the observations that took place in the early days and weeks of crawling; however, happiness dropped to just below the precrawling level after four week of crawling experience.

The spike in happiness that occurred during the observations that took place after one, two and three weeks of crawling is consistent with studies conducted by Campos et al. (1992) and Barrett and Campos (1987). This research revealed an increase in emotionality after the onset of crawling. The findings are also consistent with previous research in which new crawlers presented with a brief period of euphoria, followed by a more subdued mood once the skill of crawling was mastered (Campos et al., 1992). There are several possibilities as to why the results of the cross-sectional analysis did not attain statistical significance for happiness. One explanation for this finding might be related to the amount of crawling experience accrued. The requirement for the cross-sectional component of the current study was that crawling infants demonstrate a minimum of four weeks of crawling experience. It is possible that during the second cross-sectional observation, which took place at four weeks of crawling experience, the crawlers in this study had passed that initial period of euphoria just after crawling onset.

Campos et al. (1992) discussed the parallel between an infant's increased level of positive affect and the development of the feeling of autonomy. In the current study, early crawlers were able to fulfill goals, which potentially resulted in happy behaviors. It is possible that the early crawlers experienced increases in happiness 
because of their newfound autonomy with locomotion. Additionally, being able to readily explore their surrounding environment, obtain toys and objects in their sight, and gain proximity to others might have contributed to the increase in happiness. Additionally, the physical sensations experienced when crawling might have been a factor in the infants' initial spikes in happiness.

Limitations to the current study are that emotional attachment, parental perceptions, family involvement, and culture were not accounted for, and these factors might have contributed to the emotional development of the infants. Another limitation is that the sample was fairly small. Future studies should utilize a larger sample, and investigators are advised to consider how attachment to caregiver and siblings affects infants' emotional development as it relates to locomotion (Kochanska, 2001).

The results of the current study support the idea that the experience of independent locomotion influences a typically developing infant's emotion of happiness. These findings suggest the need for both typically and atypically developing infants to experience opportunities to locomote in order to further develop positive emotions. Infants should be provided opportunities to locomote in order to be able to act on their emotions. Additional research is needed on infant self-produced locomotion and emotional expression in naturalistic settings that include opportunities for social interaction. These future investigations will enhance our understanding of the relationship between mobility and socioemotional development.

\section{References}

Adolf, K. E., Vereijken, B., \& Denny, M. (1998). Learning to Crawl. Child Development, 69, 1299-1312. http://dx.doi.org/10.2307/1132267

Bai, D. L., \& Bertenthal, B. I. (1992). Locomotor status and the development of spatial search skills. Child Development, 63, 215-226. http://dx.doi.org/10.2307/1130914

Bell, M. A., \& Fox, N. A. (1996). Crawling experience is related to changes in cortical organization during infancy: Evidence from EEG coherence. Developmental Psychobiology, 29, 551-561. http://dx.doi.org/10.1002/ (SICI)1098-2302(199611)29:7\%3C551::AID-DEV1\%3E3.0.CO;2-T

Campos, J. J., Anderson, D. I., Barbu-Roth, M. A., Hubbard, E. M., Hertenstein, M. J., \& Witherington, D. (2000). Travel broadens the mind. Infancy, 1, 149-219. http://dx.doi.org/10.1207/S15327078IN0102_1

Campos, J. J., Bertenthal, B. I., \& Kermoian, R. (1992). Early experience and emotional development: The emergence of wariness of heights. Psychological Science, 3, 61-64. http://dx.doi.org/10.1111/j.1467-9280.1992.tb00259.x

Campos, J. J., Hiatt, S., Ramsay, D., Henderson, C., \& Svejda, M. (1978). The emergence of fear on the visual cliff. In M. Lewis, \& L. Rosenblum (Eds.), The development of affect (pp. 149-182). New York: Plenum. http://dx.doi.org/10.1007/978-1-4684-2616-8_6

Campos, J. J., Kermoian, R., \& Zumbahlen, M. R. (1992). Socioemotional transformations in the family system following infant crawling onset. New Directions for Child Development, 55, 25-40. http://dx.doi.org/10.1002/ cd.23219925504

Clearfield, M. W. (2011). Learning to walk changes infants' social interactions. Infant Behavior and Development, 34, 15-25. http://dx.doi.org/10.1016/j.infbeh.2010.04.008

Folio, M. R., \& Fewell, R. R. (1983). Peabody Developmental Motor Scales and Activity Cards, Teaching Resources. Allen, TX.

Hendrix, R. R., \& Thompson, R. A. (2010). Development of self-produced locomotion in the first year: Changes in parent perceptions and infant behavior. Infant and Child Development, 20, 288-300. http://dx.doi.org/ 10.1002/icd.695

Herbert, J., Gross, J., \& Hayne, H. (2007). Crawling is associated with more flexible memory retrieval by 9-month-old infants. Developmental $\quad$ Science, $\quad 10(2), \quad$ 183-189. http://dx.doi.org/10.1111/j.1467-7687.2007.00548.x

Kermoian, R., \& Campos, J. J. (1988). A facilitator of spatial cognitive development. Child Development, 59 , 908-917. http://dx.doi.org/10.2307/1130258

Kochanska, G. (2001). Emotional development in children with different attachment histories: The first three years. Child Development, 72(2), 474-490. http://dx.doi.org/10.1111/1467-8624.00291 
Le Compte, M. D., \& Preissle, J. (1993). Ethography and qualitative design in educational research (2nd ed.). San Diego, CA: Academic Press.

Lewis, M., \& Michalson, L. (1983). Children's emotions and moods. New York: Plenum Press. http://dx.doi.org/ 10.1007/978-1-4613-3620-4

Mahler, M., Pine, F., \& Bergman, A. (1975). The Psychological Birth of the Human Infant. New York: Basic Books.

Miles, M. B., \& Huberman, A. M. (1994). Qualitative data analysis (2nd ed.). Thousand Oaks, CA: Sage Publications.

Muhr, T., \& Friese, S. (2004). Atlas.ti, the knowledge workbench, v. 5.0: Guide and reference. Berlin: Scientific Software.

Whitney, P., \& Green, J. (2011). Changes in infants' affect related to the onset of independent locomotion. Infant Behavior and Development, 34(3), 459-466. http://dx.doi.org/10.1016/j.infbeh.2011.05.001

Zachry, A. H., \& Mitchell, A. W. (2012). Goal-directed actions and early experience with crawling. Journal of Occupation Participation and Health, 32(2), 48-55. http://dx.doi.org/10.3928/15394492-20110930-02

\section{Copyrights}

Copyright for this article is retained by the author(s), with first publication rights granted to the journal.

This is an open-access article distributed under the terms and conditions of the Creative Commons Attribution license (http://creativecommons.org/licenses/by/3.0/). 